\title{
The influence of point defects on AlGaN-based deep ultraviolet LEDs
}

Zhanhong Ma ${ }^{\mathrm{a}, \mathrm{b}}$, Abdulaziz Almalki ${ }^{\mathrm{c}}$, Xin Yang ${ }^{\mathrm{d}}$, Xing $\mathrm{Wu}^{\mathrm{d}}{ }^{\mathrm{d}}, \mathrm{Xin}_{\mathrm{Xi}}{ }^{\mathrm{a}, \mathrm{b}}$, Jing $\mathrm{Li}^{\mathrm{a}}{ }^{\mathrm{a}}$, Shan Lin ${ }^{\mathrm{a}, \mathrm{b}}$, Xiaodong Li ${ }^{\mathrm{a}, \mathrm{b}}$, Saud Alotaibi ${ }^{\mathrm{c}}$, Maryam Al huwayz ${ }^{\mathrm{c}, \mathrm{e}}$, Mohamed Henini ${ }^{\mathrm{c}}$ and Lixia Zhao ${ }^{\mathrm{a}, \mathrm{b}, *}$

${ }^{a}$ State Key Laboratory of Integrated Optoelectronics, Institute of Semiconductors, Chinese Academy of Sciences, No. A35, Qinghua East Road, Haidian District, Beijing, 100083, China

${ }^{\mathrm{b}}$ Center of Materials Science and Optoelectronic Engineering, University of Chinese Academy of Sciences, No. 19A, Yuquan Road, Shijingshan District, Beijing 100049, China

${ }^{\mathrm{c}}$ School of Physics and Astronomy, University of Nottingham, Nottingham NG7 2RD, UK

${ }^{\mathrm{d}}$ Shanghai Key Laboratory of Multidimensional Information Processing, School of Communication and Electronic Engineering, East China Normal University, Shanghai, China

${ }^{\mathrm{e}}$ Physics Department, Faculty of Science, Princess Nourah Bint Abdulrahman University, Riyadh, Saudi Arabia

Abstract AlGaN-based deep ultraviolet LEDs with high Al composition are promising for many applications, including air- or water-purification, fluorescence sensing, etc. However, to realize their full potential, it is important to understand the impact of the point defects on the device performance. Here, we investigate the defects in the $265 \mathrm{~nm}$ AlGaN-based deep ultraviolet LEDs after degradation systematically with a combination of different analytical technologies. The results show that point defects increase after the degradation. The generated defects during the stress lead to a carrier redistribution in the active region and the induced point defects during the degradation are located within the multi-quantum wells (MQWs) region, especially in the first quantum well near the $\mathrm{p}$ side of the LED chip. The dislocation lines in the MQWs region were also observed after the degradation, which can lead to the Mg diffusion along the dislocation line. These findings are important to understand the defects in AlGaN quantum wells and further improve AlGaN-based deep ultraviolet LEDs' performance. Keywords: AlGaN; deep ultraviolet LED; degradation; point defect; multiquantum wells 


\section{Introduction}

Group III-V aluminum gallium nitride $(\mathrm{AlGaN})$ semiconductors with high $\mathrm{Al}$ composition are promising for harmless, high-efficiency deep ultraviolet light-emitting diodes (DUV LEDs) [1-3]. Compared with conventional mercury gas-discharge lamps, AlGaN-based deep ultraviolet LEDs with the emission in UVC wavelength range have exceptional properties, such as tunable emission wavelength, low operating voltage, and environmental friendliness [4, 5], which have potential applications in air- or waterpurification, high-density data storage, medical diagnostics and disinfection, etc [6-8].

Till now, due to the low internal quantum efficiency (IQE) and light extraction efficiency (LEE), the maximum external quantum efficiency (EQE) of AlGaN-based deep LEDs at $275 \mathrm{~nm}$ is just 20.3\% [9] and the general EQE of DUV LEDs is only in the single-digit percentage, which is far less than InGaN-based blue LEDs (>80\%) [1015]. Many efforts have been made to reduce the threading dislocations (TDs) of AlGaN epitaxial growth $[16,17]$. With the reduction of the threading dislocation density in AIN template, the highest IQE of AlGaN quantum wells can reach $\sim 80 \%$ with the dislocation density less than $3 \times 10^{8} \mathrm{~cm}^{-2}[18,19]$.

Recently, it has been reported that the dominant nonradiative recombination center is mainly related to the point defects instead of the threading dislocations for AlGaN epilayers [20]. Chichibu et al. have suggested that the point defects (PDs) play an important role in the $\mathrm{Al}_{\mathrm{x}} \mathrm{Ga}_{1-\mathrm{x}} \mathrm{N}$-based LEDs [21, 22]. The point defects $\left(\mathrm{V}_{\mathrm{Al}}, \mathrm{V}_{\mathrm{N}}\right.$ or complexes) in $\mathrm{Al}_{\mathrm{x}} \mathrm{Ga}_{1-\mathrm{x}} \mathrm{N}$ would be generated and propagate in or around the active region during operation or stress $[23,24]$. These point defects can act as non-radiative recombination centers in the active layers and increase the Shockley-Read-Hall (SRH) recombination, resulting in the decrease of optical power of the LEDs [25, 26]. However, how point defects and dislocations influence the device performance and what is the real character of these point defects is still not clear.

In this study, we investigate the defects of AlGaN-based deep ultraviolet LEDs after the degradation using cathodoluminescence $(\mathrm{CL})$, capacitance-voltage $(\mathrm{C}-\mathrm{V})$, deeplevel transient spectroscopy (DLTS) and aberration-corrected STEM image 
measurements. The results show that high current stress can induce both the dislocation and point defects within the active region, especially in the first quantum wells (QWs) near the $\mathrm{p}$ side of the AlGaN epitaxial structure. The findings are important to understand the role of the dislocation and point defects and further improve AlGaNbased LEDs.

\section{Experimental section}

In this work, the commercially available $265 \mathrm{~nm}$ deep ultraviolet LEDs with $\sim 58 \%$ Al mole fraction in the $\mathrm{Al}_{\mathrm{x}} \mathrm{Ga}_{1-\mathrm{x}} \mathrm{N}$ MQWs were studied. The chip structure consists of a sapphire substrate, AlN buffer layer, a thick AlGaN:Si current spreading layer, three periods of AlGaN QWs, a Mg-doped AlGaN electron blocking layer, a p-AlGaN layer and a $\mathrm{p}-\mathrm{GaN}$ contact layer. The UV-C LEDs were stressed at a constant current of 100 $\mathrm{mA}$ (maximum operating current, corresponding to the current density of $\sim 160 \mathrm{~A} / \mathrm{cm}^{2}$ ) at room temperature. The $\mathrm{C}-\mathrm{V}$ characteristics were measured using a Keithley Semiconductor Characterization unit with hardware modules of 4200-SCS and a high frequency probe station. The DLTS were carried out in the temperature range of $10 \mathrm{~K}$ $440 \mathrm{~K}$ using a DLTS system composed of a Boonton 7200 capacitance meter, an Agilent 33220A pulse generator, Lake Shore 331 temperature controller and a data acquisition system. Afterwards, the metal contacts were removed chemically using a solution of $\mathrm{V}_{\mathrm{HNO} O}: \mathrm{V}_{\mathrm{HCI}}=1: 3$ and cleaned with deionized water. The CL spectra were measured at room temperature by using a Gatan Mono CL4 CL system with different electron accelerating voltages. SEM-CL was measured on the $\mathrm{Al}_{\mathrm{x}} \mathrm{Ga}_{1-\mathrm{x}} \mathrm{N}$-based fresh and stressed DUV LED chip at room temperature in the same system. The TEM specimens of the LED chip were prepared using a focused ion beam-scanning electron microscope system (Helios NanoLab 460 HP). STEM images and EDX mapping were recorded using a double aberration corrected transmission electron microscope (JEM-ARM300F, JEOL). 


\section{Results and discussion}

Since the penetration depth of the electrons increase with increasing the electron beam energies [27], to understand the distribution of the radiative or non-radiative recombination centers at different depths, we measured the cathodoluminescence spectrum with different electron accelerating voltages. In this case, the structural and optical properties of different layers in the multilayer structures can be identified. Fig. 1(a) shows the CL of the fresh LED measured with different energies of the incident electrons, where the accelerating voltages are at $3 \mathrm{kV}, 5 \mathrm{kV}$ and $7 \mathrm{kV}$, respectively. This allows us to identify the depth dependence of the radiative and non-radiative recombination center distributions along the c-axis [0001].
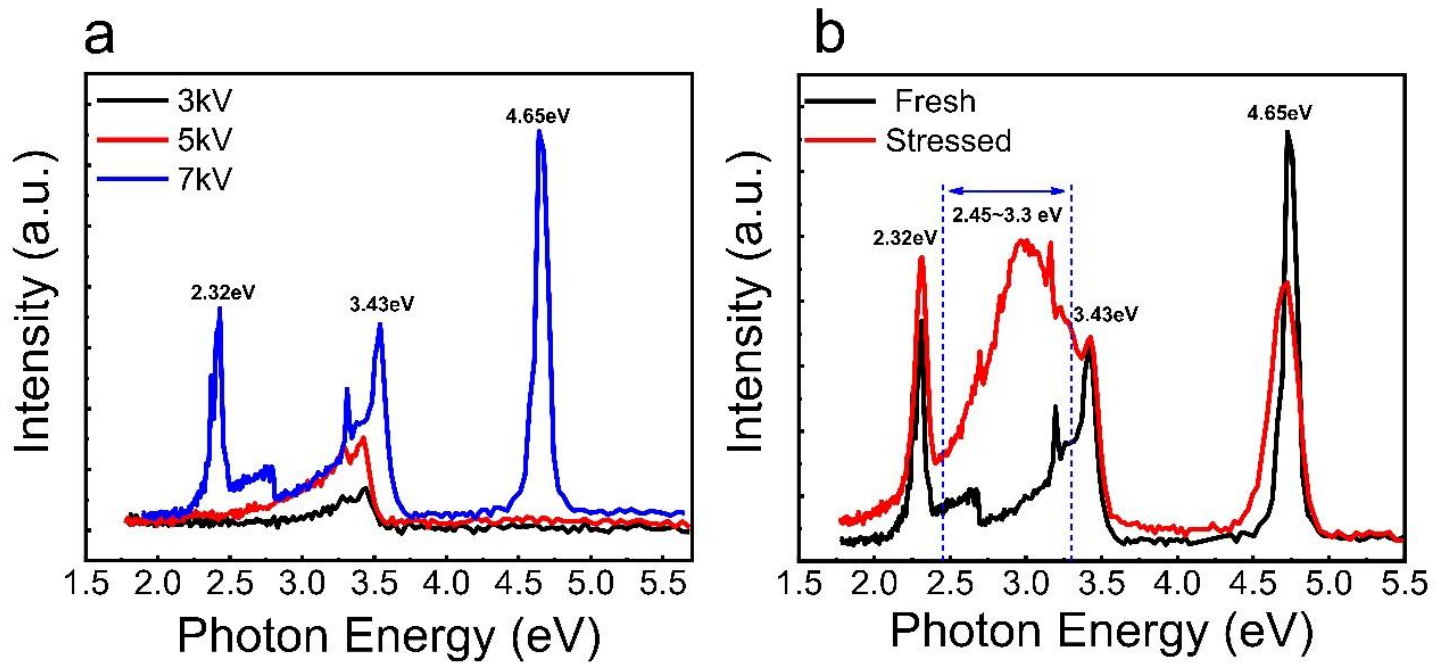

Fig. 1. The CL spectra of DUV LED chip. (a) CL spectra of fresh DUV LEDs measured under different electron accelerating voltages, $3 \mathrm{kV}, 5 \mathrm{kV}$ and $7 \mathrm{kV}$. (b) CL spectra of DUV LEDs before and after degradation, measured under $7 \mathrm{kV}$ electron accelerating voltage.

When the operation voltages are $3 \mathrm{kV}$ and $5 \mathrm{kV}$, there is almost no emission from the QWs with the corresponding energy $4.65 \mathrm{eV}(265 \mathrm{~nm})$, indicating that the majority of the collected CL signals are from the regions above the QWs of the UV-C LED chip. With increasing the operation voltage to $7 \mathrm{kV}$, the emission of $\mathrm{AlGaN}$ QWs at $4.65 \mathrm{eV}$ increase dramatically, suggesting that they are from the quantum well region. Using Monte Carlo simulations, the penetration depths of the electrons in the LED chip at 3 $\mathrm{kV}, 5 \mathrm{kV}$, and $7 \mathrm{kV}$ are $\sim 50 \mathrm{~nm}, 130 \mathrm{~nm}$ and 180-200 nm, respectively [28, 29]. 
Combining with the TEM image of the chip epitaxial structure (as shown in Fig. S2), the CL spectra measured at electron accelerating voltage of $7 \mathrm{kV}$ are in good agreement with the quantum well structure. In addition, the peak position at $3.43 \mathrm{eV}$ corresponds to the band edge emission peak of $\mathrm{GaN}$ and the peak position at $2.32 \mathrm{eV}$ is due to the second order diffraction of the main emission peak. The spikes in all the CL spectra before and after stress may be related to the impurities in AlGaN materials.

Using the fresh LED chip as the control sample, the CL spectra of the stressed chip were investigated. Fig. 1(b) shows the CL spectra of the fresh and stressed LED measured at electron accelerating voltage of $7 \mathrm{kV}$, the peak intensity from the AlGaN quantum well decreases significantly after stress, similar to the previously reported results [30]. But the emissions at the lower energies increase after stress. The band edge emission peak of GaN and the double diffraction of the main emission peak still exist. Besides, an obvious broad emission in the energy range of $2.45-3.30 \mathrm{eV}$ appears for the stressed sample compared with the control sample, which is related to the increased point defects in the quantum well area during the stress.

To investigate the carrier distribution in the active region for the DUV LED before and after the stress, the $C-V$ characteristics were measured at $1 \mathrm{MHz}$, as shown in the inset of Fig. 2(a). The capacitance of the LED increases under a large reverse bias but decreases under a small reverse bias after stress. The three steps in the $C$ - $V$ curve in the reverse bias become more obvious after stress. In addition, it seems that there is a right shift after the degradation, indicating that the effective negative charges in the p-region become less, which makes the space charge region move to the p-side. The different behavior of capacitance change under reverse bias indicates the redistribution of the carriers in the active region after stress. 

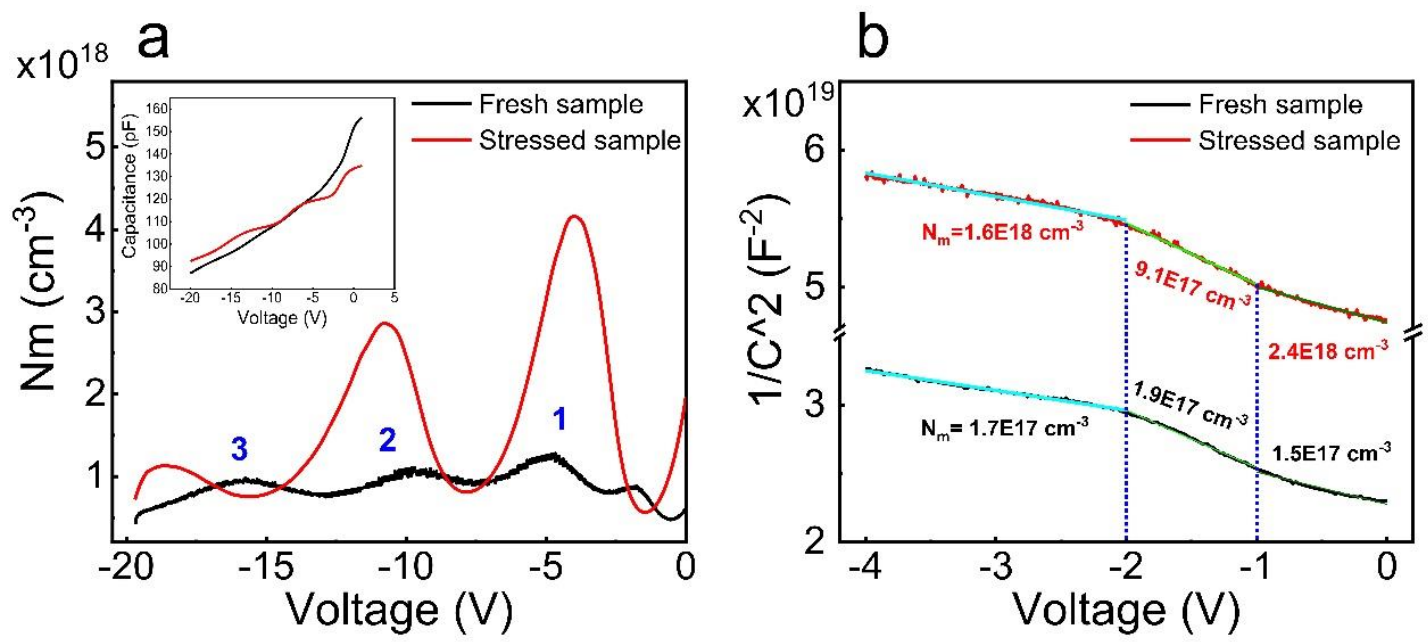

Fig. 2. (a) The carrier distribution (ACD) for the fresh and stressed DUV LEDs at various reverse biases obtained from $C-V$ curves. The inset shows capacitance-voltage $(\mathrm{C}-\mathrm{V})$ curves of the fresh and stressed DUV LED measured at $1 \mathrm{MHz}$. (b) Relationship between the reciprocal of the square of the capacitance and voltage (from -4 to $0 \mathrm{~V}$ ). Different colors are used for linear fitting to obtain the apparent carrier concentration.

Fig. 2(a) shows the apparent carrier distribution (ACD) calculated from the $C-V$ curves of DUV LED using the following equation [31],

$$
\frac{\partial C_{j}\left(V_{r}\right)}{\partial V_{r}}=-\frac{C_{j}^{3}\left(V_{r}\right)}{e \varepsilon A^{2}} \cdot \frac{1}{N_{m}}
$$

where $\varepsilon$ represents the permittivity, $\mathrm{A}$ is the area of the junction, $\mathrm{V}_{r}$ is the applied reverse bias, and $\mathrm{N}_{\mathrm{m}}$ denotes the apparent carrier concentration. The three peaks (marked by Arabic numerals) correspond to the three quantum wells of the LED. The ACD of the fresh LED is very uniform in the MQWs. But after stress, the carrier distribution in the MQWs becomes inhomogeneous, as shown in Fig. 2(a) (red line). Furthermore, the change of quantum well near p-region (the first QW, marked 1) is more significant than the other two quantum wells, the maximum value of the ACD for first QW changes from $1.20 \times 10^{18} \mathrm{~cm}^{-3}$ to $4.16 \times 10^{18} \mathrm{~cm}^{-3}$. The I-V characteristic curves of the UVC-LED (Fig. 1S(b)) show that the leakage current in the reverse bias region and the subthreshold region increase after the stress and the ideality factor calculated from the I-V curves also increases after stress, indicating the generation of the point 
defects or dislocation [30]. Accordingly, the increase of the carrier concentration in the AlGaN QWs after stress is mainly due to the capture of carriers by defects generated during the stress operation.

To further investigate the variation of the active area near the p-region, the relationship between the inverse of the square of the capacitance and voltage (from - 4 $\mathrm{V}$ to $0 \mathrm{~V}$ ) was extracted from $C-V$ curves, which is plotted in Fig. 2(b). Since the active area (MQWs) of the LED epitaxial structure is normally undoped, the apparent carrier concentration of the first QW area can be obtained by linear fitting $1 / C^{2}-V$ curve in the reverse bias voltage range $-4 \mathrm{~V}$ to $0 \mathrm{~V}$ as below,

$$
\partial\left(\frac{1}{C_{T}^{2}}\right) / \partial V_{r}=\frac{2}{A^{2} e \varepsilon N_{m}}
$$

The results show that the linear fitted average apparent carrier concentration $\mathrm{N}_{\mathrm{m}}$ for both the fresh and stressed sample can be divided into three voltage sections, $-4 \mathrm{~V}$ to $2 \mathrm{~V},-2 \mathrm{~V}$ to $-1 \mathrm{~V}$ and $-1 \mathrm{~V}$ to $0 \mathrm{~V}$, respectively. The apparent carrier concentrations in these three regions for the stressed LED are 9.4, 4.8, and 16 times to that of the fresh sample. Therefore, the ACD in MQWs had a redistribution process after stress, showing an increase trend during the stress, and this behavior is more significant in the top quantum well of the active area close to the p-type side. As reported previously, the electric current stress would cause the generation of the defects in the AlGaN based LED chips [25, 30], and these defects related deep levels can capture the electrons or holes [20], resulting in the increase of the ACD in the AlGaN MQWs.

To further investigate the possible deep levels in the region near the $\mathrm{p}$ side, DLTS spectra were obtained for the fresh and the stressed samples. We performed two DLTS measurements for the fresh and stressed LEDs under different reverse bias voltages: one with a filling voltage $\left(\mathrm{V}_{\mathrm{P}}\right)$ of $0 \mathrm{~V}$ and a reverse measuring voltage $\left(\mathrm{V}_{\mathrm{R}}\right)$ of $-0.5 \mathrm{~V}$ (corresponding to the depletion region under $-0.5 \mathrm{~V}$ to $0 \mathrm{~V}$ ), and the other with a filling voltage of $0 \mathrm{~V}$ and a reverse measuring voltage of $-4 \mathrm{~V}$, as shown in Fig. S3 (corresponding to the depletion region under $-4 \mathrm{~V}$ to $0 \mathrm{~V}$ ). 

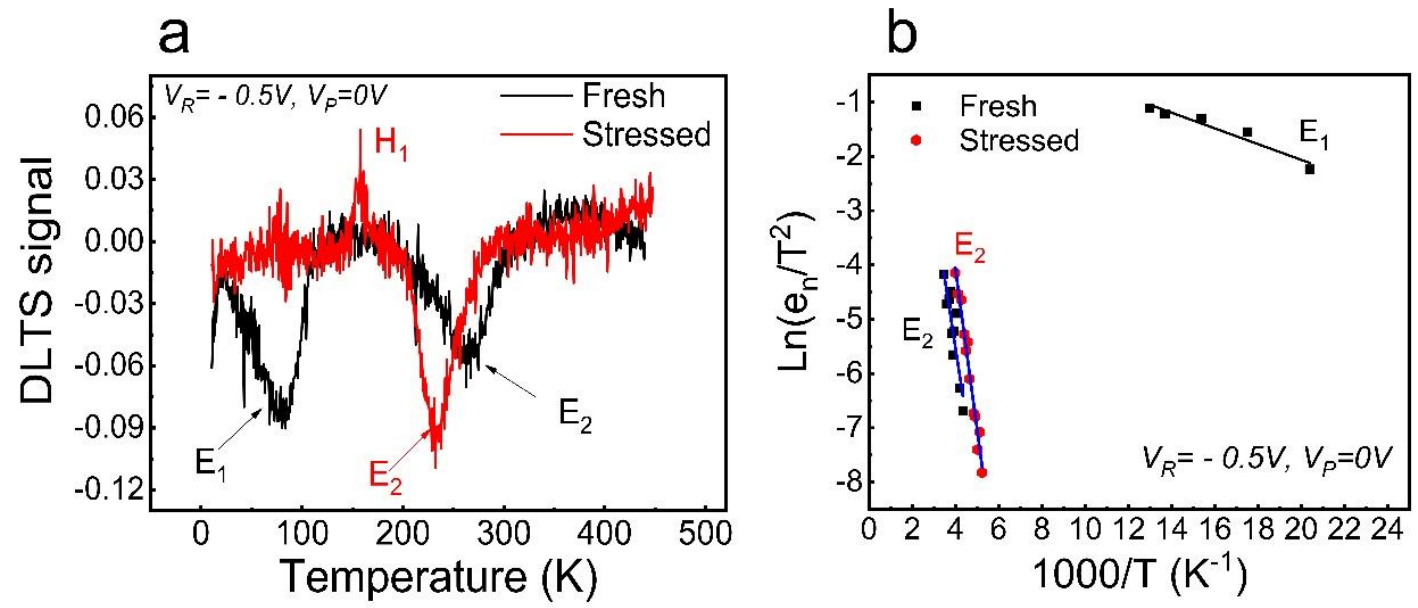

Fig. 3. (a) The typical capacitance deep-level transient spectroscopy (DLTS) spectra of the fresh and stressed DUV LED obtained under the following conditions: reverse bias $V_{R}=-0.5 \mathrm{~V}$, filling pulse $\mathrm{V}_{\mathrm{p}}=0 \mathrm{~V}$, and pulse duration $\mathrm{t}_{\mathrm{p}}=1 \mathrm{~ms}$ at rate window of $500 \mathrm{~s}^{-1}$. (b) Arrhenius plot of the energy levels detected in DLTS; $\mathrm{T}$ is the temperature, and $\mathrm{e}_{\mathrm{n}}$ is the emission rate corresponding to the maximum of the trap peak observed.

Fig. 3(a) shows the DLTS spectra for $V_{P}=0 \mathrm{~V}$ and $V_{R}=-0.5 \mathrm{~V}$ before and after stress to evaluate the area adjacent to the $\mathrm{p}$ side. There are two negative peaks (labeled as $\mathrm{E}_{1}$ and $E_{2}$ ) at 80 and $265 \mathrm{~K}$ for the fresh device, respectively. While for the stressed LED, there is no $E_{1}$ signal and $E_{2}$ shifts toward lower temperature of $233 \mathrm{~K}$. In addition, a small positive peak (labeled as $\mathrm{H}_{1}$ ) appears at $\sim 145 \mathrm{~K}$ for the stressed LED, which becomes more prominent under a reverse bias voltage of $-4 \mathrm{~V}$, as shown in Fig. S3. For DLTS, a positive peak is related to minority-carriers trap levels, whereas a negative peak is related to majority-carriers trap levels $[32,33]$. For the unintentionally doped AlGaN multi-quantum wells, the minority carriers are the holes and the majority are the electrons [32].

Fig. 3(b) shows the Arrhenius plots of these traps with the parameters listed in Table 1. During the stress, the activation energy of trap $E_{1}$ is about $0.010 \mathrm{eV}$ (corresponding to the peak at a temperature $\sim 100 \mathrm{~K}$ ), indicating a shallow character [20], which may be related to the point defect P1 in Ref.20. The disappearance of the negative peak $\mathrm{E}_{1}$ and the emergence of the new positive peak $\mathrm{H}_{1}$ indicates that there may be a donoracceptor complex trap in the active area after the stress. The activation energy of the 
trap $\mathrm{H}_{1}$ is $\sim 0.1 \mathrm{eV}$, which is consistent with the activation energy of Mg-related acceptors [32], such as $\mathrm{Mg}_{\mathrm{Al}}$ [34] or $\mathrm{Mg}_{\mathrm{Ga}}$ [35]. The appearance of the threading dislocations through the whole quantum well after stress may cause the $\mathrm{Mg}$ diffusion along the dislocation line [36], which leads to the Mg-related acceptor traps, such as the deep level $\mathrm{H}_{1}$.

\section{Table 1}

Apparent activation energy, capture cross section, and trap concentration of the defects observed in the fresh and stressed DUV LED devices. Recording condition: $\mathrm{V}_{\mathrm{R}}=-0.5 \mathrm{~V}, \mathrm{~V}_{\mathrm{P}}=0 \mathrm{~V}$ and the duration of the filling pulse was $t_{p}=1 \mathrm{~ms}$.

\begin{tabular}{lccccc}
\hline Samples & $\begin{array}{c}\text { Reverse } \\
\text { bias(V) }\end{array}$ & Trap & $\begin{array}{c}\text { Activation Energy } \\
(\mathbf{e V})\end{array}$ & $\begin{array}{c}\text { Trap concentration } \\
\mathbf{c m}^{-3}\end{array}$ & $\begin{array}{c}\text { Capture-cross section } \\
\mathbf{c m}^{\mathbf{2}}\end{array}$ \\
\hline \multirow{2}{*}{ Fresh } & $\mathrm{Vr}=-0.5$ & $\mathrm{E}_{1}$ & $0.010 \pm 0.002$ & $7.4 \mathrm{E} 13$ & $8.8 \mathrm{E}-22$ \\
\hline \multirow{2}{*}{ Stressed } & $\mathrm{E}_{2}$ & $0.20 \pm 0.04$ & $4.5 \mathrm{E} 13$ & $4.6 \mathrm{E}-20$ \\
\hline
\end{tabular}

The activation energy of the trap $\mathrm{E}_{2}$ is in the range $0.20-0.25 \mathrm{eV}$, which is related to the $\mathrm{N}$ vacancies [37]. The trap $\mathrm{E}_{2}$ concentration increases by more than 10 times from $4.5 \times 10^{13} \mathrm{~cm}^{-3}$ to $9.9 \times 10^{14} \mathrm{~cm}^{-3}$ after degradation. The capture-cross section of $\mathrm{E}_{2}$ also increases from $4.6 \times 10^{-20} \mathrm{~cm}^{2}$ to $8.6 \times 10^{-19} \mathrm{~cm}^{2}$. In addition, the shift to the lower temperature and the increase of the activation energy indicate that the trapping probability of electrons increases after the stress. It needs to be noted that the $\mathrm{H}_{1}$ under $-4 \mathrm{~V}$ bias decreases after stress shown in Fig. S3, indicating that the degradation may also lead to other possible donors, such as $\mathrm{Mg}_{\mathrm{Al}}-\mathrm{V}_{\mathrm{N}}, \mathrm{Mg}_{\mathrm{Ga}}-\mathrm{V}_{\mathrm{N}}$ complex [38], which will result in a self-compensation effect. Furthermore, because the formation energy of $\mathrm{V}_{\mathrm{Al}}$ in $\mathrm{AlGaN}$ is smaller than that of $\mathrm{V}_{\mathrm{Ga}}$ in $\mathrm{GaN}$, the deep level $\mathrm{H}_{2}$ in Fig. $\mathrm{S} 3$ may be related to the $\mathrm{V}_{\mathrm{Al}}[20,39,40]$.

Fig. 4 shows the schematic of the band diagram of the MQWs for the UVC-LED with the enlarged images of the first quantum well region (circled with red dotted rectangle) before and after stress. According to DLTS results, the generated new donor and acceptor related levels in the band gap after stress are depicted in the diagram. 
These electron trap levels generated after stress lead to the decrease of the effective negative charge in the p side near quantum wells, which lead to the observed right shift of the $\mathrm{C}-\mathrm{V}$ curve after the degradation (Fig. 2(a)). In addition, the donor-acceptor transitions between $\mathrm{N}$ vacancies to $\mathrm{Mg}$ acceptors after degradation could also result in the increase of the deep level emission around $3.0 \mathrm{eV}$ for $\mathrm{AlGaN}$ materials with the $\mathrm{Al}$ composition $\sim 55 \%$ (Fig.1(b)) [41, 42]. However, it has also been reported that $\mathrm{Al}$ vacancies and related complex are responsible for the deep emission between $2.84 \mathrm{eV}$ and $2.92 \mathrm{eV}$ for AlGaN alloy with Al composition 56\%-68\% [43]. Therefore, the energy range of $2.45-3.30 \mathrm{eV}$ observed in the CL spectra may be the overall effect of the above point defects discussed in the DLTS, which will be further discussed elsewhere.

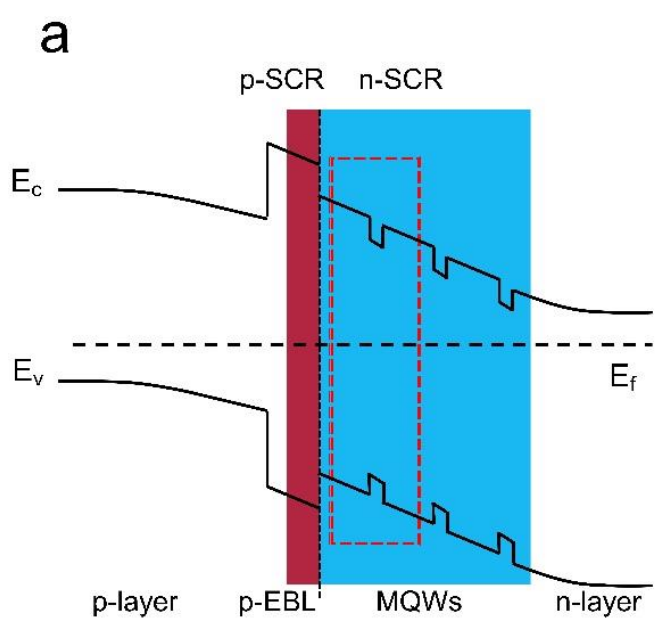

b

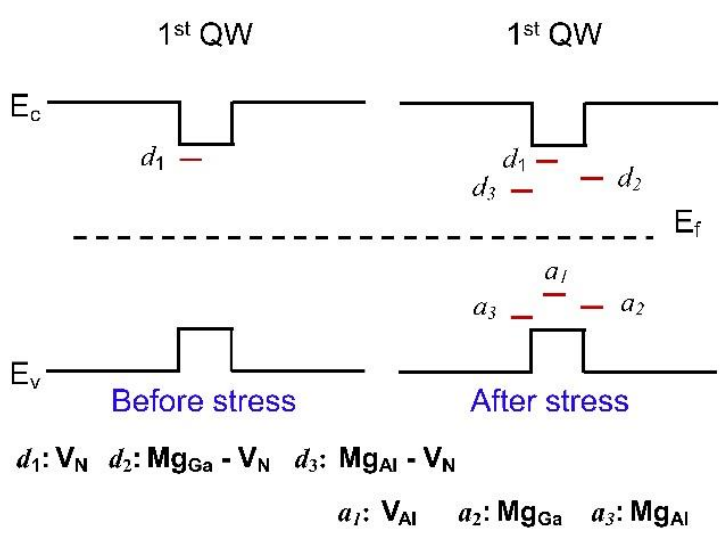

Fig. 4. (a) Schematic of the band diagram of the studied UV-C LED with space-charge regions at the pn-junction. (b)The band diagram of the first quantum well before and after stress, (enlarged image of the region circled by red dotted rectangle in Fig. 4(a)). The donor related levels marked as ' $d$ ', and the acceptor related levels marked as 'a'.

To further evaluate the epitaxial structure of the UVC-LED chip intuitively after degradation, especially the quantum well area, the cross section of the epitaxial structure was characterized by TEM and EDX mapping. Fig. 5(a) shows the HAADFSTEM image of the MQWs region of the fresh LED, and the inset shows the TEM image of the epitaxial structure for the fresh LED. This allows us to directly identify the depth dependence of the defects. There are little dislocations or defects in the MQWs before the stress. However, after the stress, two dislocation lines appear and 
pass through the whole quantum well region, as shown in Fig. 5(c). To investigate the effect of the threading dislocation on the MQWs, the EDX mapping of the MQWs region were measured by an overlay of $\mathrm{Al}$ (green), Ga (yellow) and $\mathrm{N}$ (orange) signals, as shown in Fig. 5(b) and 5(d). By comparing the EDX mapping images of the fresh and stressed samples, there are some variations of the composition in the first and second quantum well and barrier near the $\mathrm{p}$ side of the epitaxial structure. The composition also changes along the dislocation, as marked with the red circles in Fig. 5(d). The TEM and EDX mapping results suggest that the MQWs of the LED epitaxial structure have been strongly affected after stress, especially close to the $\mathrm{p}$ side.
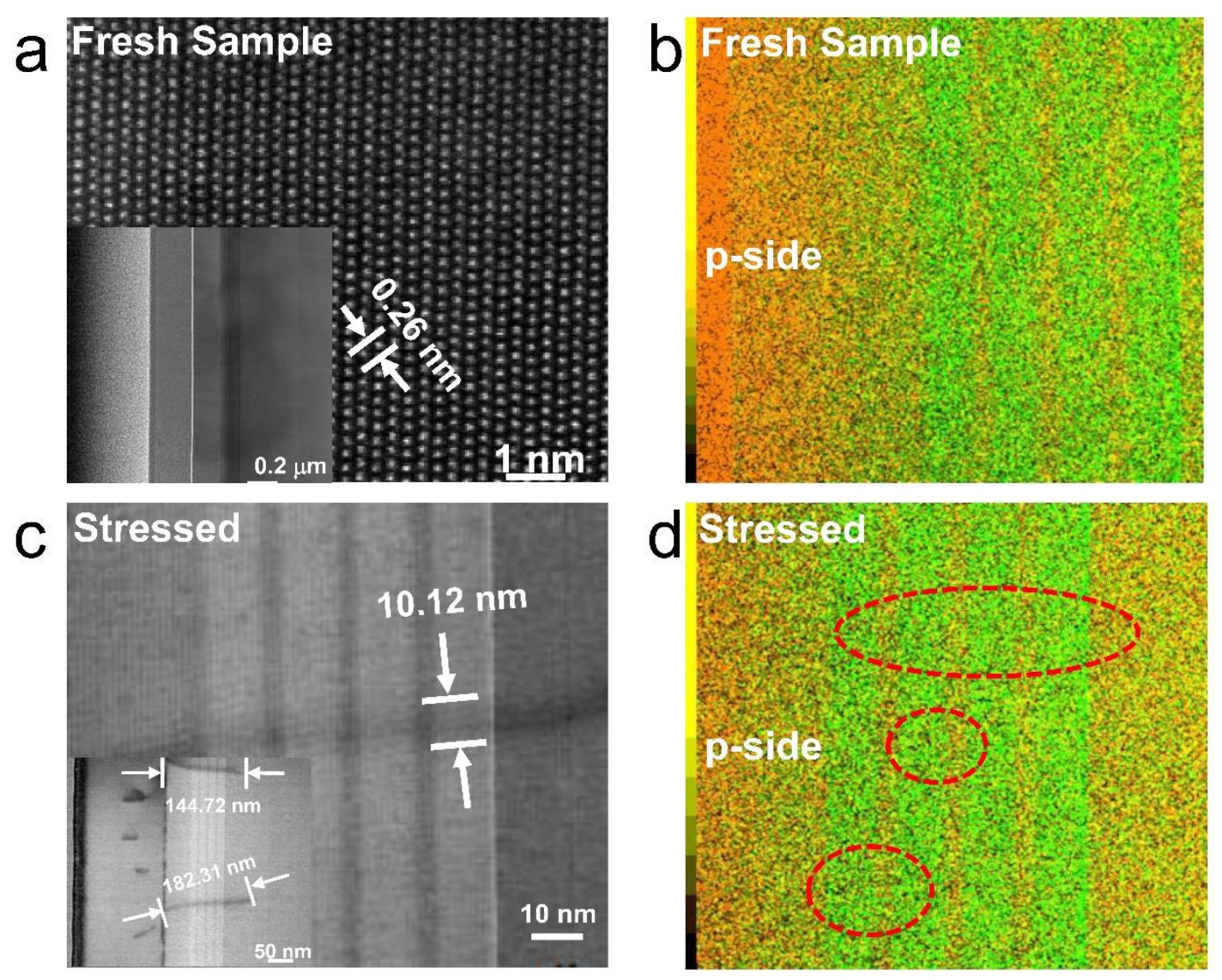

Fig. 5. (a) Schematic of the band diagram of the studied UV-C LED with space-charge regions at the pn-junction. (b)The band diagram of the first quantum well before and after stress, (enlarged image of the region circled by red dotted rectangle in Fig. 4(a)). The donor related levels marked as ' $\mathrm{d}$ ', and the acceptor related levels marked as 'a'.

In general, threading dislocations (TDs) in InGaN/GaN multi-quantum-well (MQW) 
active structures would act as nonradiative recombination centers and degrade the emission intensity $[44,45]$, which strongly contribute to the leakage current of forward and reverse I-V regions in LEDs [46, 47]. The electrical and optical properties of the InGaN/GaN MQWs tend to decrease with increasing the dislocation densities [48]. But for AlGaN/GaN MQWs, the internal quantum efficiency (IQE) of the QWs on AlN bulk substrates with a low threading dislocation density (TDD, TDD $<10^{5} \mathrm{~cm}^{-2}$ ) is almost the same as that of QWs on sapphire substrates with a high TDD (approximately $10^{9}$ $10^{10} \mathrm{~cm}^{-2}$ ) [49]. The emission dark spots attributed to TDs were not observed in the CL images of AlGaN/AlN QWs in the entire temperature region [20]. The reported results suggest that TDs are not the dominant nonradiative recombination centers for AlGaNbased LEDs. However, here, the TEM results show that the dislocation lines did appear in the MQWs region after the stress, which may influence the point defects as well, e.g. resulting in the $\mathrm{Mg}$ diffusion along the dislocation line and cause some Mg-related acceptor traps [36], degrade the AlGaN-based LEDs [50].

\section{Conclusion}

In this study, we investigated the point defects and dislocations by comparing the AlGaN-based ultraviolet LEDs before and after degradation systematically using several different analytical techniques, including cathodoluminescence, deep-level transient spectroscopy and transmission electron microscope. The results show that the electrical current stress induced point defects are located within the multiple quantum wells region, especially in the first quantum well near the $p$ side of the LED chip. The increased point defects density during the stress will cause a carrier redistribution process. In addition, the DLTS results indicate that these relative point defects may act as the electron traps and hole traps. Moreover, the TEM (EDX mapping) also provides some evidence of the $\mathrm{Mg}$ diffusion along the dislocation line and lead to $\mathrm{Mg}$-related traps. By investigating the defects of the fresh and the stressed UV-C LED epitaxial structure, the failure mechanisms for the stressed sample regarding to the point defects and dislocations have been identified. This study is important to further improve the performance of AlGaN-based LEDs. 


\section{Acknowledgment}

This study is funded by the National Natural Science Foundation of China (Grants No. 61774148, 11974343) and National Basic Research and High Technology Program of China (Grants No. 2017YFB0403601 and 2017YFB0403602). M.H. and MAH are grateful for the support by a grant from the deanship of scientific research, Princess Nourah Bint Abdulrahman University, Riyadh, Kingdom of Saudi Arabia.

\section{References}

[1] Y. Nagasawa, A. Hirano, A Review of AlGaN-Based Deep-Ultraviolet Light-Emitting Diodes on Sapphire, Applied Sciences, 8 (2018) 1264.

[2] S.F. Chichibu, K. Hazu, T. Onuma, A. Uedono, Collateral evidence for an excellent radiative performance of AlxGa1-xN alloy films of high AlN mole fractions, Applied Physics Letters, 99 (2011).

[3] H. Hirayama, N. Maeda, S. Fujikawa, S. Toyoda, N. Kamata, Recent progress and future prospects of AlGaN-based high-efficiency deep-ultraviolet light-emitting diodes, Japanese Journal of Applied Physics, 53 (2014).

[4] N. Susilo, S. Hagedorn, D. Jaeger, H. Miyake, U. Zeimer, C. Reich, B. Neuschulz, L. Sulmoni, M. Guttmann, F. Mehnke, C. Kuhn, T. Wernicke, M. Weyers, M. Kneissl, AlGaNbased deep UV LEDs grown on sputtered and high temperature annealed AlN/sapphire, Applied Physics Letters, 112 (2018) 041110.

[5] Y. Guo, J. Yan, Y. Zhang, J. Wang, J. Li, Enhancing the light extraction of AlGaN-based ultraviolet light-emitting diodes in the nanoscale, Journal of Nanophotonics, 12 (2018) 1.

[6] D. Lee, J.W. Lee, J. Jang, I.-S. Shin, L. Jin, J.H. Park, J. Kim, J. Lee, H.-S. Noh, Y.-I. Kim, Y. Park, G.-D. Lee, Y. Park, J.K. Kim, E. Yoon, Improved performance of AlGaN-based deep ultraviolet light-emitting diodes with nano-patterned AlN/sapphire substrates, Applied Physics Letters, 110 (2017) 191103.

[7] H. Hirayama, T. Yatabe, N. Noguchi, T. Ohashi, N. Kamata, 231-261 nm AlGaN deepultraviolet light-emitting diodes fabricated on AlN multilayer buffers grown by ammonia pulseflow method on sapphire, Applied Physics Letters, 91 (2007).

[8] M. Khizar, Z.Y. Fan, K.H. Kim, J.Y. Lin, H.X. Jiang, Nitride deep-ultraviolet light-emitting diodes with microlens array, Applied Physics Letters, 86 (2005).

[9] T. Takano, T. Mino, J. Sakai, N. Noguchi, K. Tsubaki, H. Hirayama, Deep-ultraviolet lightemitting diodes with external quantum efficiency higher than $20 \%$ at $275 \mathrm{~nm}$ achieved by improving light-extraction efficiency, Applied Physics Express, 10 (2017).

[10] Y.J. Sung, M.S. Kim, H. Kim, S. Choi, Y.H. Kim, M.H. Jung, R.J. Choi, Y.T. Moon, J.T. Oh, H.H. Jeong, G.Y. Yeom, Light extraction enhancement of AlGaN-based vertical type deepultraviolet light-emitting-diodes by using highly reflective ITO/Al electrode and surface roughening, Optics express, 27 (2019) 29930-29937.

[11] A. Pandey, W.J. Shin, X. Liu, Z. Mi, Effect of electron blocking layer on the efficiency of AlGaN mid-ultraviolet light emitting diodes, Optics express, 27 (2019) A738-A745.

[12] N. Maeda, M. Jo, H. Hirayama, Improving the Light-Extraction Efficiency of AlGaN 
DUV-LEDs by Using a Superlattice Hole Spreading Layer and an Al Reflector, physica status solidi (a), 215 (2018).

[13] Y. Kashima, N. Maeda, E. Matsuura, M. Jo, T. Iwai, T. Morita, M. Kokubo, T. Tashiro, R. Kamimura, Y. Osada, H. Takagi, H. Hirayama, High external quantum efficiency (10\%) AlGaN-based deep-ultraviolet light-emitting diodes achieved by using highly reflective photonic crystal on p-AlGaN contact layer, Applied Physics Express, 11 (2018).

[14] D. Lee, J.W. Lee, J. Jang, I.-S. Shin, L. Jin, J.H. Park, J. Kim, J. Lee, H.-S. Noh, Y.-I. Kim, Y. Park, G.-D. Lee, Y. Park, J.K. Kim, E. Yoon, Improved performance of AlGaN-based deep ultraviolet light-emitting diodes with nano-patterned AlN/sapphire substrates, Applied Physics Letters, 110 (2017).

[15] G.-D. Hao, M. Taniguchi, N. Tamari, S.-i. Inoue, Enhanced wall-plug efficiency in AlGaNbased deep-ultraviolet light-emitting diodes with uniform current spreadingp-electrode structures, Journal of Physics D: Applied Physics, 49 (2016).

[16] M. Imura, K. Nakano, G. Narita, N. Fujimoto, N. Okada, K. Balakrishnan, M. Iwaya, S. Kamiyama, H. Amano, I. Akasaki, T. Noro, T. Takagi, A. Bandoh, Epitaxial lateral overgrowth of AlN on trench-patterned AlN layers, Journal of Crystal Growth, 298 (2007) 257-260.

[17] U. Zeimer, V. Kueller, A. Knauer, A. Mogilatenko, M. Weyers, M. Kneissl, High quality AlGaN grown on ELO AlN/sapphire templates, Journal of Crystal Growth, 377 (2013) 32-36.

[18] H. Hirayama, S. Fujikawa, N. Kamata, Recent Progress in AlGaN-Based Deep-UV LEDs, Electronics and Communications in Japan, 98 (2015) 1-8.

[19] H. Hirayama, S. Fujikawa, N. Noguchi, J. Norimatsu, T. Takano, K. Tsubaki, N. Kamata, 222-282 nm AlGaN and InAlGaN-based deep-UV LEDs fabricated on high-quality AlN on sapphire, physica status solidi (a), 206 (2009) 1176-1182.

[20] S. Ichikawa, M. Funato, Y. Kawakami, Dominant Nonradiative Recombination Paths and Their Activation Processes in AlxGa1-xN -related Materials, Physical Review Applied, 10 (2018).

[21] S.F. Chichibu, H. Miyake, Y. Ishikawa, M. Tashiro, T. Ohtomo, K. Furusawa, K. Hazu, K. Hiramatsu, A. Uedono, Impacts of Si-doping and resultant cation vacancy formation on the luminescence dynamics for the near-band-edge emission of Al0.6Ga0.4N films grown on AlN templates by metalorganic vapor phase epitaxy, Journal of Applied Physics, 113 (2013).

[22] S.F. Chichibu, K. Hazu, Y. Ishikawa, M. Tashiro, T. Ohtomo, K. Furusawa, A. Uedono, S. Mita, J. Xie, R. Collazo, Z. Sitar, Excitonic emission dynamics in homoepitaxial AlN films studied using polarized and spatio-time-resolved cathodoluminescence measurements, Applied Physics Letters, 103 (2013).

[23] N. Liu, Q. Wang, B. Li, J. Wang, K. Zhang, C. He, L. Wang, L. Song, X. Cao, B. Wang, D. Lin, X. Liu, W. Zhao, Z. Gong, Z. Chen, Point-Defect Distribution and Transformation Near the Surfaces of AlGaN Films Grown by MOCVD, The Journal of Physical Chemistry C, 123 (2019) 8865-8870.

[24] K. Kanegae, H. Fujikura, Y. Otoki, T. Konno, T. Yoshida, M. Horita, T. Kimoto, J. Suda, Deep-level transient spectroscopy studies of electron and hole traps in n-type GaN homoepitaxial layers grown by quartz-free hydride-vapor-phase epitaxy, Applied Physics Letters, 115 (2019).

[25] J. Glaab, J. Haefke, J. Ruschel, M. Brendel, J. Rass, T. Kolbe, A. Knauer, M. Weyers, S. Einfeldt, M. Guttmann, C. Kuhn, J. Enslin, T. Wernicke, M. Kneissl, Degradation effects of the 
active region in UV-C light-emitting diodes, Journal of Applied Physics, 123 (2018) 104502.

[26] R.I. Made, Y. Gao, G.J. Syaranamual, W.A. Sasangka, L. Zhang, X.S. Nguyen, Y.Y. Tay, J.S. Herrin, C.V. Thompson, C.L. Gan, Characterisation of defects generated during constant current InGaN-on-silicon LED operation, Microelectronics Reliability, (2017).

[27] J. Goldstein, D. Newbury, D. Joy, C. Lyman, P. Echlin, E. Lifshin, L. Sawyer, J. Michael, Scanning Electron Microscopy and X-Ray Microanalysis, Springer, (2002).

[28] F.C. Massabuau, S.L. Rhode, M.K. Horton, T.J. O'Hanlon, A. Kovacs, M.S. Zielinski, M.J. Kappers, R.E. Dunin-Borkowski, C.J. Humphreys, R.A. Oliver, Dislocations in AlGaN: Core Structure, Atom Segregation, and Optical Properties, Nano Lett, 17 (2017) 4846-4852.

[29] P. Hovington, D. Drouin, R. Gauvin, D.C. Joy, N. Evans, CASINO: A new monte Carlo code in C language for electron beam interactions-part III: Stopping power at low energies, Scanning, 19 (1997) 29-35.

[30] Z. Ma, H. Cao, S. Lin, X. Li, L. Zhao, Degradation and failure mechanism of AlGaNbased UVC-LEDs, Solid-State Electronics, 156 (2019) 92-96.

[31] N.C. Chen, W.C. Lien, Y.S. Wang, H.H. Liu, Capacitance-Voltage and Current-Voltage Measurements of Nitride Light-Emitting Diodes, IEEE Transactions on Electron Devices, 54 (2007) 3223-3228.

[32] D. Monti, M. Meneghini, C.D. Santi, G. Meneghesso, E. Zanoni, J. Glaab, J. Rass, S. Einfeldt, F. Mehnke, J. Enslin, T. Wernicke, M. Kneissl, Defect-Related Degradation of AlGaNBased UV-B LEDs, IEEE Transactions on Electron Devices, PP (2016) 1-6.

[33] D.V. Lang, Deep-level transient spectroscopy: A new method to characterize traps in semiconductors, Journal of Applied Physics, 45 (1974) 3023-3032.

[34] T.L. Tansley, R.J. Egan, Point-defect energies in the nitrides of aluminum, gallium, and indium, Physical Review B, 45 (1992) 10942-10950.

[35] B. Monemar, P.P. Paskov, G. Pozina, C. Hemmingsson, J.P. Bergman, T. Kawashima, H. Amano, I. Akasaki, T. Paskova, S. Figge, D. Hommel, A. Usui, Evidence for two Mg related acceptors in GaN, Physical review letters, 102 (2009) 235501.

[36] S. Usami, N. Mayama, K. Toda, A. Tanaka, M. Deki, S. Nitta, Y. Honda, H. Amano, Direct evidence of $\mathrm{Mg}$ diffusion through threading mixed dislocations in $\mathrm{GaN} \mathrm{p}-\mathrm{n}$ diodes and its effect on reverse leakage current, Applied Physics Letters, 114 (2019).

[37] Z.Q. Fang, D.C. Look, W. Kim, Z. Fan, A. Botchkarev, H. Morkoç, Deep centers in n-GaN grown by reactive molecular beam epitaxy, Applied Physics Letters, 72 (1998) 2277-2279.

[38] G. Miceli, A. Pasquarello, Self-compensation due to point defects in Mg-doped GaN, Physical Review B, 93 (2016).

[39] T.A. Henry, A. Armstrong, A.A. Allerman, M.H. Crawford, The influence of Al composition on point defect incorporation in AlGaN, Applied Physics Letters, 100 (2012).

[40] K. Laaksonen, M.G. Ganchenkova, R.M. Nieminen, Vacancies in wurtzite GaN and AlN, J Phys Condens Matter, 21 (2009) 015803.

[41] U. Kaufmann, M. Kunzer, H. Obloh, M. Maier, C. Manz, A. Ramakrishnan, B. Santic, Origin of defect-related photoluminescence bands in doped and nominally undoped GaN, Physical Review B, 59 (1999) 5561-5567.

[42] M.L. Nakarmi, N. Nepal, J.Y. Lin, H.X. Jiang, Photoluminescence studies of impurity transitions in Mg-doped AlGaN alloys, Applied Physics Letters, 94 (2009).

[43] N. Nepal, M.L. Nakarmi, J.Y. Lin, H.X. Jiang, Photoluminescence studies of impurity 
transitions in AlGaN alloys, Applied Physics Letters, 89 (2006).

[44] S.Y. Karpov, Y.N. Makarov, Dislocation effect on light emission efficiency in gallium nitride, Applied Physics Letters, 81 (2002) 4721-4723.

[45] Y.S. Choi, J.H. Park, S.S. Kim, H.J. Song, S.H. Lee, J.J. Jung, B.T. Lee, Effects of dislocations on the luminescence of $\mathrm{GaN} / \mathrm{InGaN}$ multi-quantum-well light-emitting-diode layers, Materials Letters, 58 (2004) 2614-2617.

[46] S. Usami, Y. Ando, A. Tanaka, K. Nagamatsu, M. Deki, M. Kushimoto, S. Nitta, Y. Honda, H. Amano, Y. Sugawara, Y.-Z. Yao, Y. Ishikawa, Correlation between dislocations and leakage current of p-n diodes on a free-standing GaN substrate, Applied Physics Letters, 112 (2018).

[47] S.W. Lee, D.C. Oh, H. Goto, J.S. Ha, H.J. Lee, T. Hanada, M.W. Cho, S.K. Hong, H.Y. Lee, S.R. Cho, J.W. Choi, J.H. Choi, J.H. Jang, J.E. Shin, J.S. Lee, T. Yao, Analysis of the relation between leakage current and dislocations in GaN-based light-emitting devices, physica status solidi (c), 4 (2007) 37-40.

[48] S. Dang, C. Li, M. Lu, H. Guo, Z. He, Threading dislocation density effect on the electrical and optical properties of InGaN light-emitting diodes, Optik, 155 (2018) 26-30.

[49] S. Ichikawa, Y. Iwata, M. Funato, S. Nagata, Y. Kawakami, High quality semipolar $\left(11^{-} 02\right) \mathrm{AlGaN} / \mathrm{AlN}$ quantum wells with remarkably enhanced optical transition probabilities, Applied Physics Letters, 104 (2014).

[50] S.-N. Lee, H.S. Paek, J.K. Son, H. Kim, K.K. Kim, K.H. Ha, O.H. Nam, Y. Park, Effects of $\mathrm{Mg}$ dopant on the degradation of InGaN multiple quantum wells in AlInGaN-based light emitting devices, Journal of Electroceramics, 23 (2008) 406-409. 